Investigator of Canada, says that although the number of diagnosed hepatitis $\mathrm{C}$ cases is down, the prevalence remains very high, and 'that doesn't strike me as a success story." Information about CSC's hepatitis testing methods is too patchy, he warned. "We don't know if the number of undiagnosed cases is up."

The apparent decline in cases may be related to a $10 \%$ budget cut at CSC in 2012, according to a written statement from the physician who declined to be named: "The prison health care system is under stress with increasing prisoner numbers and decreased funding."

The fixed sum allocated for hepatitis $\mathrm{C}$ therapy is insufficient, he writes. "Patients are prioritized according to severity of disease. Sometimes further money becomes available later in the financial year. But there is no guarantee. Each penitentiary is told how many patients they can treat and are provided with drugs accordingly. The system appears to run out of money for hepati- tis drugs early in the financial year usually after three to four months."

According to figures obtained by CMAJ in 2012, CSC's bill for hepatitis drug treatment increased almost sevenfold between 2005 and 2010. Then, in 2011, CSC achieved a $40 \%$ reduction in hepatitis $\mathrm{C}$ treatment costs, although it stated that the number of diagnosed cases decreased only $8 \%$ and the prevalence dropped only $3 \%$. The cost savings was achieved through "a bulk purchase of hepatitis C medication," CSC explained.

In 2012, when the CSC's overall budget was cut, the service began preparing for a new generation of hepatitis $\mathrm{C}$ drugs that cost an estimated $\$ 60000$ per treatment, or almost twice as much as the old ones.

Under the Access to Information law, Glenn Betteridge, a Canadian Treatment Access Council policy researcher and former prisoner health lawyer, obtained the August 2015 CSC formulary of medications for federal inmates. It indicated that the CSC is restricting access to the latest drugs and controlling treatment costs, he says.

"The formulary tells us that CSC is treating the new drugs as 'exceptional medications' for which prescribing is taken out of the hands of the doctor and is in the hands of an administrative decision-maker who may not have resources to review cases in a timely manner," Betteridge says.

In response, CSC's Halfper stated that "treatment initiations are based on recommendations from a medical specialist. CSC balances the demand for treatment with patient safety within defined resources and in the context of patients with complex health care needs."

The service relies on "one national and five regional pharmacists who have the authority to make final case management decisions," CSC added. - Paul Christopher Webster, Toronto, Ont.

CMAJ 2015. DOI:10.1503/cmaj.109-5181

\title{
Nunavut acts on recommendations for suicide prevention
}

$\mathrm{N}$ early 40 years after losing his older brother to suicide, Nunavut's health minister will lead the territory's suicide prevention efforts. Health Minister Paul Okalik will chair a cabinet committee on quality of life. The move is in response to recommendations of an inquest into the high rate of suicide in Nunavut. Nearly 500 people have completed suicide since the territory was created.

Premier Peter Taptuna and ministers of housing, education and family services will also sit on the committee. With the help of a new associate deputy minister, the committee will manage "new monies and a costing process to identify the needed funds" for new staff, training programs and other supports to implement the recommendations of the inquest and Nunavut's existing suicide prevention strategy and action plan.

The premier did not, however, announce a specific amount for the strategy or programs to reduce the suicide rate in Nunavut, which is 9.8 times the national average. Instead, he indicated the money will come from existing budgets.
The coroner's jury recommended that Taptuna declare suicide a public health emergency — something the premier did not do, although that designation could help trigger federal help. Among the jury's other recommendations was giving a specific individual the responsibility for the suicide prevention file, with dedicated resources and a secretariat to implement the suicide prevention strategy.

Taptuna's announcement appeared to adopt the broad intent of many of the jury's recommendations. He committed to cross-governmental programs to reduce the risk factors that precipitate suicide, and to broadening the delivery of the Applied Suicide Intervention Skills Training (ASIST) program, which expert witnesses at the inquiry recommended as one of a suite of initiatives the territory should continue.

Taptuna also acknowledged that it is possible to prevent suicide, one of the first times a senior Inuit leader has done so. One of the critical factors in Quebec's ability to reduce its suicide rates, expert witness Brian Mishara testified at the inquest, was a change in societal attitudes that had previously accepted suicide as a normal and inevitable aspect of Quebec society.

Mishara, director of the Centre for Research and Intervention on Suicide and Euthanasia at the Université du Quebec à Montréal, urged Nunavut's leadership to issue strong statements rejecting suicide as an acceptable way to deal with pain. Taptuna and Okalik's statements suggest they took Mishara's recommendation to heart.

"There is no single reason why someone may try to end their life, but in large part, this is preventable," Taptuna told the legislature.

For his part, Okalik promised that he and "many of his colleagues" would take an ASIST workshop in November, a recommendation another expert witness made at the inquest. "As members of this legislative assembly, we are each committed to doing our part in prevention and reducing the stigma," said Okalik. — Laura Eggertson, Ottawa, Ont.

CMAJ 2015. DOI:10.1503/cmaj.109-5186 